Article

\title{
Molecular Evidence for Hybrid Origin and Phenotypic Variation of Rosa Section Chinenses
}

\author{
Chenyang Yang, Yujie Ma, Bixuan Cheng, Lijun Zhou, Chao Yu* , Le Luo, Huitang Pan \\ and Qixiang Zhang
}

Beijing Key Laboratory of Ornamental Plants Germplasm Innovation \& Molecular Breeding, National Engineering Research Center for Floriculture, Beijing Laboratory of Urban and Rural Ecological Environment, Key Laboratory of Genetics and Breeding in Forest Trees and Ornamental Plants of Ministry of Education, School of Landscape Architecture, Beijing Forestry University, Beijing 100083, China; cheny6622@foxmail.com (C.Y.); 13466780515@163.com (Y.M.); chengbixuan@126.com (B.C.); 13020021576@163.com (L.Z.); luole15804@163.com (L.L.); pantakki@126.com (H.P.); zqxbjfu@126.com (Q.Z.)

* Correspondence: yuchao@bjfu.edu.cn

Received: 26 June 2020; Accepted: 18 August 2020; Published: 25 August 2020

\begin{abstract}
Rosa sect. Chinenses (Rosaceae) is an important parent of modern rose that is widely distributed throughout China and plays an important role in breeding and molecular biological research. $R$. sect. Chinenses has variable morphological traits and mixed germplasm. However, the taxonomic status and genetic background of sect. Chinenses varieties remain unclear. In this study, we collected germplasm resources from sect. Chinenses varieties with different morphological traits. Simple sequence repeat (SSR) markers, chloroplast markers, and single copy nuclear markers were used to explore the genetic background of these germplasm resources. We described the origin of hybridization of rose germplasm resources by combining different molecular markers. The results showed that the flower and hip traits of different species in $R$. sect. Chinenses were significantly different. The SSR analysis showed that the two wild type varieties have different genetic backgrounds. The double petal varieties of $R$. sect. Chinenses could be hybrids of two wild type varieties. A phylogenetic analysis showed that the maternal inheritance of sect. Chinenses varieties had two different origins. To some extent, variation in the morphological traits of double petal species of $R$. sect. Chinenses reflects the influence of cultivation process. This study emphasizes that different genetic markers vary in their characteristics. Therefore, analyzing different genetic markers in could provide an insight into highly heterozygous species.
\end{abstract}

Keywords: Rosa sect. Chinenses; China rose; morphological traits; molecular marker; genetic diversity; phylogenetic analysis

\section{Introduction}

Modern rose is the largest group of ornamental plants in the world, with more than 30,000 cultivars [1]. Rosa sect. Chinenses (Rosaceae) represents one of the hybrid parents of modern rose. Rosa contains approximately 200 species, more than $95 \%$ of which belong to the subgenus Rosa. Species in the subgenus Rosa can be divided into 10 sections, $R$. sects Pimpinellifoliae, Rosa, Cinnamomeae, Synstylae, Chinenses (Indicae), Banksianae, Laevigatae, Bracteatae, Caninae, and Carolinae [2]. A total of 82 Rosa species can be found in China, with species in $R$. sect. Chinenses endemic to China. $R$. sect. Chinenses contains three species: Rosa chinensis Jacq, Rosa odorata (Andr.) Sweet, and Rosa lucidissima Lévl. Three varieties of $R$. chinensis are currently recognized: $R$. chinensis var. chinensis, var. spontanea (Rehd. et Wils.) Yu et Ku, var. semperflorens (Curbs) Koehne. While four varieties of $R$. odorata are 
recognized: R. odorata var. odorata, var. gigantea (Crep.) Rehd. et Wils., var. pseudlindica (Lindl.) Rehd., var. erubescens (Focke) Yu et Ku. R. chinensis var. spontanea and R. odorata var. gigantea are considered as original species, both of which have single petal. [3]. Roses in China were first described in the Han Dynasty [4] and then spread all over China, leading to the breeding of diverse cultivars. In China's Ancient Rose, 180 old garden roses from ancient China were recorded, including 29 different $R$. chinensis varieties and 22 different $R$. odorata varieties, which have single or double petals. Varieties with double petals are considered as more cultivated [1]. Molecular studies have shown that the varieties with double petal of $R$. sect. Chinenses might be hybrids of $R$. odorata var. gigantea and $R$. chinensis. Rosa multiflora might be involved in multiple hybridization events of $R$. chinensis cultivars [5].

With unique ornamental characters, China roses became important plant materials in breeding and molecular studies. However, the description of double petal varieties of $R$. chinensis and $R$. odorata is not sufficiently clear in the Flora of China [3]. A large number of putative natural or artificial hybrid varieties have been found in the wild, and the genetic relationship among these species has not yet been completely elucidated. A previous study suggested that these species were transitional populations generated from breeding [6] or the hybrid offspring of wild and cultivated populations.

The phenotypic variation of Rosa species is highly complex and results from the interaction between genes and their environment. Morphological markers have allowed for the study of genetic diversity and taxonomy of some Rosa species [7-9]. Compared with morphological markers, molecular markers are not affected by environmental factors, and they can directly reflect the differences and similarities between genetic materials. Diverse molecular markers are currently available, but different markers have distinct functions. To date, hundreds of simple sequence repeats (SSRs) had been developed for Rosa [10,11], and these have been applied to the classification of wild and cultivated roses [12,13]. In addition, single-copy nuclear genes (SCGs) can also be effectively used to research the characteristics of parental inheritance, orthologs, and high genetic polymorphism of Rosa. GAPDH is one of the SCGs and it is the most commonly used in the genus Rosa [14,15] that is more suitable for taxonomic categories above class [16]. With the release of the rose genome [17,18], SCGs are being more widely applied [19]. Chloroplast genes have been shown to be more conserved than nuclear genes [20]. And chloroplast genes are maternally inherited [21], while nuclear genes are inherited from both parents. Thus, combining the two types of markers could be used to identify and infer the maternal contributor to hybrid roses [5,9]. Integrating the advantages of different genetic markers could provide further insight into the genetic diversity of Rosa species. In this study, a series of $R$. sect. Chinenses germplasm resources was collected. The genetic diversity of these resources was analyzed using different genetic markers, and the genetic background and taxonomic status of these materials were clarified.

\section{Materials and Methods}

\subsection{Experimental Materials}

In this study, 31 rose accessions were used, including eight $R$. odorata (Andr.) Sweet, five $R$. chinensis Jacq and $18 R$. sect. Chinenses varieties with transition phenotypes (Table 1). Most plant materials were collected from Yunnan Province, with the exception of single petal varieties (Figure 1). The collections were cultivated at Kunming Yang Chinese Rose Gardening Co., Ltd. (Kunming, China), and traits were observed for successive years to confirm the stability of phenotypic characters and determine whether morphological differences existed among the materials. Among the phenotypic characters, different accessions of $R$. sect. Chinenses displayed significant differences in several quantitative traits. Flower and hip-related traits in rose are affected by both environment and genotype [22-24]. Therefore, the materials used in this study were cultivated in an open field and had grown in the same environment for many years. This allowed the traits to stabilize. Thus, the phenotypic variations described in this study were primarily derived from the genotype. 
Table 1. Classification of rose accessions.

\begin{tabular}{|c|c|c|c|c|}
\hline Accession Number & Collection Locality & Taxonomic Assignation & Section & Haplotype Assignation \\
\hline 1_1 & Dali, Yunnan, China & Rosa odorata var. gigantea & Chinenses & H1 \\
\hline $1 \_2$ & Dali, Yunnan, China & R. odorata var. gigantea & Chinenses & $\mathrm{H} 1$ \\
\hline $1 \overline{35}$ & Kunming, Yunnan, China & R. odorata var. gigantea & Chinenses & $\mathrm{H} 1$ \\
\hline $1 \_7$ & Dali, Yunnan, China & R. odorata var. odorata & Chinenses & H1 \\
\hline $1 \_28$ & Dali, Yunnan, China & R. odorata var. odorata & Chinenses & $\mathrm{H} 1$ \\
\hline $1 \_33$ & - & Rosa chinensis var. spontanea & Chinenses & H5 \\
\hline $1 \_15$ & Wenchuan, Sichuan, China & $R$. chinensis var. spontanea & Chinenses & H5 \\
\hline 9_12 & - & R. chinensis var. spontanea & Chinenses & H5 \\
\hline 1_39 & - & R. chinensis var. chinensis & Chinenses & $\mathrm{H} 2$ \\
\hline $2 \_2$ & - & R. chinensis 'Old Blush' & Chinenses & $\mathrm{H} 7$ \\
\hline $1 \_10$ & Kunming, Yunnan, China & R. sect. Chinenses complex & Chinenses & $\mathrm{H} 2$ \\
\hline $1 \_13$ & Puer, Yunnan, China & R. sect. Chinenses complex & Chinenses & $\mathrm{H} 3$ \\
\hline 1_14 & Puer, Yunnan, China & R. sect. Chinenses complex & Chinenses & $\mathrm{H} 4$ \\
\hline 1_16 & LIjiang, Yunnan, China & R. sect. Chinenses complex & Chinenses & H6 \\
\hline $1 \_17$ & LIjiang, Yunnan, China & R. sect. Chinenses complex & Chinenses & $\mathrm{H} 2$ \\
\hline 1_18 & Tengchong, Yunnan, China & R. sect. Chinenses complex & Chinenses & H7 \\
\hline 1_20 & Kunming, Yunnan, China & R. sect. Chinenses complex & Chinenses & $\mathrm{H} 2$ \\
\hline $1 \_21$ & - & R. sect. Chinenses complex & Chinenses & $\mathrm{H} 2$ \\
\hline $1 \_23$ & - & R. sect. Chinenses complex & Chinenses & $\mathrm{H} 7$ \\
\hline $1 \_24$ & Dali, Yunnan, China & R. sect. Chinenses complex & Chinenses & $\mathrm{H} 1$ \\
\hline $1 \_25$ & Dali, Yunnan, China & R. sect. Chinenses complex & Chinenses & $\mathrm{H} 2$ \\
\hline $1 \_26$ & - & R. sect. Chinenses complex & Chinenses & $\mathrm{H} 7$ \\
\hline 57 & - & Rosa sericea & Pimpinellifoliae & H12 \\
\hline 10 & - & Rosa xanthina & Pimpinellifoliae & H11 \\
\hline
\end{tabular}

Because the Flora of China lacks a detailed description of double petal varieties of $R$. chinensis and $R$. odorata [1], they have not been subordinately classified. Varieties with unclear taxonomic status but similar to $R$. odorata or $R$. chinensis are difined as $R$. sect. Chinenses complex. $R$. odorata var. gigantea and $R$. chinensis var. spontanea with single petal character were the original species of $R$. sect. Chinenses. The combination of $R$. odorata var. gigantea and $R$. chinensis was designated the wild type [3], and the rest of the sect. Chinenses accessions have characteristics of double petal. They were denoted as cultivated type [1]. 


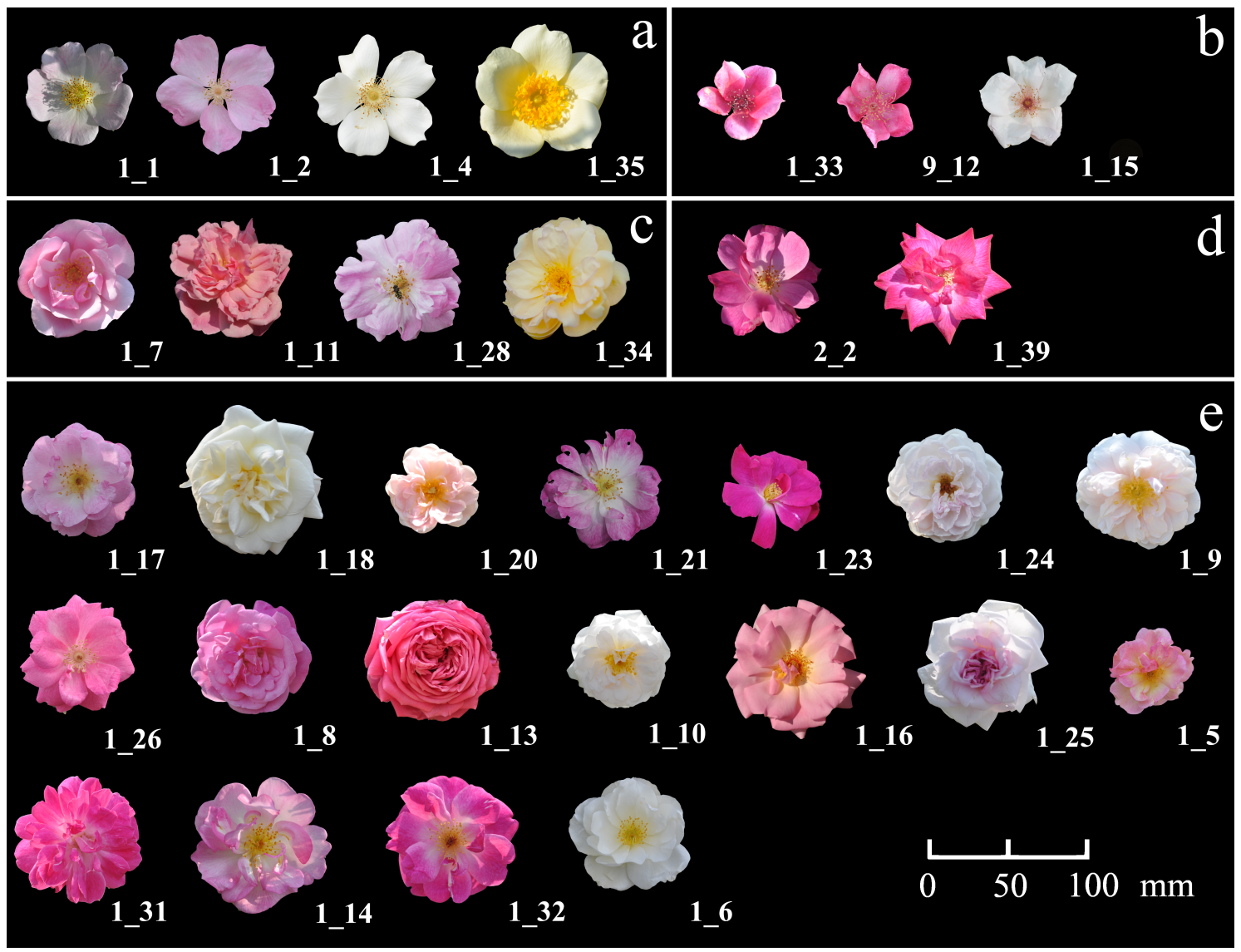

Figure 1. Variation of rose accession flowers: (a) $R$. odorata var. gigantea (b) $R$. chinensis var. spontanea (c) R. odorata var. odorata (d) $R$. chinensis var. chinensis (e) $R$. sect. Chinenses complex. While (a,b) are wild type rose accessions, $(\mathbf{c}-\mathbf{e})$ are the cultivated types of rose accessions.

\subsection{Measurement and Analysis of Phenotypic Traits}

Thirteen floral and hip phenotypic traits of $R$. sect. Chinenses were measured (Table 2). A single-factor analysis of variance (ANOVA) was used to compare the differences of traits among species. A nonparametric Kolmogorov-Smirnov test (K-S test) and median test were used to analyze the significance of phenotypic differences among species. A principal component analysis (PCA) was conducted using FactoMineR Package [25] implemented in R v. 3.6.3.

Table 2. A single-factor analysis of variance (ANOVA) of quantitative traits of $R$. sect. Chinenses.

\begin{tabular}{|c|c|c|c|c|c|c|c|}
\hline \multirow{2}{*}{ Traits } & \multicolumn{5}{|c|}{ Median (mm) } & \multicolumn{2}{|c|}{$p$ Value } \\
\hline & $\begin{array}{c}\text { R. odorata } \\
\text { var. gigantea }\end{array}$ & $\begin{array}{c}\text { R. odorata } \\
\text { var. odorata }\end{array}$ & $\begin{array}{c}\text { R. chinensis } \\
\text { var. spontanea }\end{array}$ & $\begin{array}{l}\text { R. chinensis } \\
\text { var. chinensis }\end{array}$ & $\begin{array}{l}\text { Sect. Chinenses } \\
\text { Complex }\end{array}$ & $\begin{array}{l}\text { Median } \\
\text { Test }\end{array}$ & $\begin{array}{l}\text { K-S } \\
\text { Test }\end{array}$ \\
\hline Hip length & $21.70^{a}$ & $17.44^{a b}$ & $20.22^{a}$ & $14.74^{b c}$ & $13.20^{c}$ & $<0.0001$ & $<0.0001$ \\
\hline Hip width & $21.93^{a}$ & $16.16^{a}$ & $19.06^{a}$ & $14.11^{b}$ & $12.94^{c}$ & $<0.0001$ & $<0.0001$ \\
\hline Peduncle length & $11.32^{a}$ & $14.25^{a b}$ & $5.03^{c}$ & $18.67^{b d}$ & $24.65^{d}$ & $<0.0001$ & $<0.0001$ \\
\hline Sepal length & $27.90^{a}$ & $17.52^{b}$ & $16.56^{b}$ & $18.56^{b}$ & $22.42^{a b}$ & 0.0021 & 0.0292 \\
\hline Sepal width & $6.25^{a}$ & $6.10^{a}$ & $4.02^{b}$ & $4.78^{a}$ & $6.71^{a}$ & 0.0038 & $<0.0001$ \\
\hline Flower diameter & $80.05^{a}$ & $78.32^{a}$ & $56.97^{b}$ & $62.14^{b c}$ & $67.14^{c}$ & $<0.0001$ & $<0.0001$ \\
\hline Number of petals & $5^{a}$ & $29^{b}$ & $5^{a}$ & $22^{b}$ & $28^{b}$ & $<0.0001$ & $<0.0001$ \\
\hline Pistil length & $3.24^{a b}$ & $3.43^{a b}$ & $2.35^{a}$ & $3.80^{b}$ & $5.19^{c}$ & $<0.0001$ & $<0.0001$ \\
\hline Stamen length & 7.88 & 7.06 & 5.84 & 5.40 & 6.43 & 0.1080 & 0.0091 \\
\hline
\end{tabular}

Letters in the table represent ANOVA homogeneous subsets based on a median test. The significance level is 0.05 . 


\subsection{DNA Extraction, Amplification, and Sequencing}

Total DNA was extracted from the young leaves of annual branches collected from plant material described above. The leaf material was dried with silica gel and stored at room temperature. Total DNA was extracted using the Plant Genome Extraction Kit (DP320) from Tiangen Biotech Co., Ltd. (Beijing, China) and was used as the template for downstream analysis. PCR amplification of the DNA template was performed using primers for three types of markers, including SSRs, chloroplast DNA, and SCGs. SSRs and chloroplast primers were adopted and screened from previous studies [26-29]. SCGs were screened from the rose genome sequence. First, this procedure used 959 amino acid sequences of Arabidopsis SCGs that were shared among Arabidopsis, Populus, Vitis, and Oryza [30]. These sequences were then compared against the $R$. chinensis 'Old Blush' genome [18] using TBLASTN [31]. Sequences with an identity $>60 \%$ and only one hit were selected as the candidate SCG. 363 SCGs were selected. Amplification primers were designed using two genes from each chromosome among the 363 SCGs. Each amplified fragment was established to be between $600 \mathrm{bp}$ and $1500 \mathrm{bp}$ and contained at least one exon region. Finally, four SCG markers were screened for this experiment (Table 3).

Table 3. Genetic diversity of gene markers.

\begin{tabular}{cccccc}
\hline Locus Name & RefSeq & Length & Polymorphism Sites & Nucleotide Polymorphism & Favorite Model \\
\hline$m a t K$ & - & $533 \mathrm{bp}$ & $10(1.9 \%)$ & 0.00378 & K81uf + G \\
$a t p B-r b c L$ & - & $594 \mathrm{bp}$ & $9(1.5 \%)$ & 0.00171 & K81uf + G \\
trnL-trnF & - & $961 \mathrm{bp}$ & $26(2.7 \%)$ & 0.00412 & K81uf $+\mathrm{G}$ \\
ZIP4 & LOC112169932 & $720 \mathrm{bp}$ & $53(7.4 \%)$ & 0.01008 & $\mathrm{HKY}+\mathrm{I}+\mathrm{G}$ \\
AP5 & LOC112197902 & $1371 \mathrm{bp}$ & $44(3.2 \%)$ & 0.00127 & $\mathrm{HKY}+\mathrm{I}+\mathrm{G}$ \\
SQD1 & LOC112170325 & $767 \mathrm{bp}$ & $35(4.6 \%)$ & 0.00557 & $\mathrm{HKY}+\mathrm{I}+\mathrm{G}$ \\
ALG8 & LOC112182822 & $622 \mathrm{bp}$ & $47(7.6 \%)$ & 0.01134 & $\mathrm{HKY}+\mathrm{I}+\mathrm{G}$ \\
\hline
\end{tabular}

The PCR reagent from the $2 \times$ PCR Master Mix from Beijing BioDee Biotechnology Co., Ltd. (Beijing, China) was used. PCR amplifications were performed in $20 \mu \mathrm{L}$ reactions containing the following: $1 \mu \mathrm{L}$ DNA template, $1 \mu \mathrm{L}$ upstream primer, $1 \mu \mathrm{L}$ downstream primer, and $10 \mu \mathrm{L} 2 \times$ PCR Master Mix, and were brought to volume using ddH2O. The PCR amplification program was as follows: pre-denaturation at $95^{\circ} \mathrm{C}$ for $2 \mathrm{~min}, 30$ cycles of denaturation at $95{ }^{\circ} \mathrm{C}$ for $30 \mathrm{~s}$, annealing for $30 \mathrm{~s}$, extension at $72{ }^{\circ} \mathrm{C}$ for $60 \mathrm{~s}$, and a final extension at $72{ }^{\circ} \mathrm{C}$ for $5 \mathrm{~min}$. The annealing temperature was set according to the primers used. The primer information is listed in Table S1. The amplification products of SSR markers were detected using a 3730XL DNA analyzer (Applied Biosystems, ThermoFisher Scientific, Waltham, MA, USA), and the electrophoretic results were assessed by GeneMapper software [32] to identify the size of each fragment. The amplification products of SCG markers and chloroplast gene markers were directly sequenced. The resulting sequences were assembled, and the mismatch sites were manually corrected.

\subsection{Analysis of Genetic Diversity}

The results of SSR analysis were statistically analyzed using Genealex v. 6.5 [33], and the number of different alleles (Na) and polymorphic information content (PIC) of each variety were calculated. Heterozygous excess was detected using Bottleneck v. 1.2, with the TPM model, 80\% of Stepwise Mutation Model (SMM), and 10\% of Infinite Alleles Model (IAM) [34]. The genetic structure was analyzed using STRUCTURE v2.3.4 [35], and eight independent simulations at each level of genetic clustering ( $\mathrm{K}$; for $\mathrm{K}=2-7$ ) were performed. A Markov chain Monte Carlo (MCMC) analysis for each simulation repeats 1,200,000 times after a burn-in period of 200,000. The best $\mathrm{K}$ was estimated using the online tool Structure Harvester [36], and a sampling analysis for each $\mathrm{K}$ was conducted using CLUMPP [37].

Multiple sequence alignment of SCGs and chloroplast markers was performed using MAFFT [38], and the results were inputted into DnaSP v. 6.12 [39] for a statistical analysis of nucleotide 
polymorphisms and haplotype. A phylogenetic analysis was conducted on chloroplast gene markers and SCG markers using PhyloSuite [40]. For SCG markers, the conserved region of each gene was obtained by a BLAST search against 'Old Blush' genome, and the non-conserved region was manually deleted. Chloroplast marker sequences were compared against the chloroplast genomes of $R$. odorata var. gigantea (KF753637) [41], R. chinensis var. spontanea (MG523859) [42], 'Old Blush' (CM009590) [18], R. multiflora (MG727863) [43], and R. lucieae (MG727864) [43], and the reference sequence were aligned with sequenced results. After the sequences were assembled and partitioned, the models of sequence evolution were tested by PartitionFinder [44] under the corrected Akaike's Information Criterion (AICc). The phylogenetic analysis used the Bayesian analysis implemented by MrBayes [45]. The program was run with MCMC chain generations $=2,000,000$, sampling frequency $=100$, burn-in fraction $=0.25$, the number of chains $=4$ and the number of runs $=2$. In addition, the frequency of chloroplast haplotypes was counted, and the haplotype network was constructed using the software PopART 1.7 [46] based on the Median Joining method [47].

\section{Results}

\subsection{Variance Analysis of Phenotypic Traits}

Most quantitative traits differed significantly among varieties (Table 2). The results of the K-S test and median test showed significant differences in nine traits among different species. Multiple comparisons revealed that the hip of the wild type accessions was significantly larger than those of the cultivated type accessions. The flower diameter and sepal size of $R$. odorata were significantly larger than those of $R$. chinensis. The $R$. sect. Chinenses complex had a mid-sized flower diameter and sepal size. Additionally, the pistil and peduncle length differed among varieties.

The PCA was performed, and the data was graphed for phenotypic traits (Figure 2). The first two principal components explained $95.6 \%$ of phenotypic variation. Principal component one (PC1) $(49.6 \%)$ primarily explained the effects of hip length and width, peduncle length, petal number, and length of pistil and stamen. Principal component two (PC2) (36\%) primarily explained the effects of sepal length and width and flower diameter. The figure showed that PC2 could effectively distinguish the phenotypic differences between $R$. odorata var. gigantea and $R$. chinensis var. spontanea, while the distribution of phenotypes of cultivated type partially overlapped with wild type. 


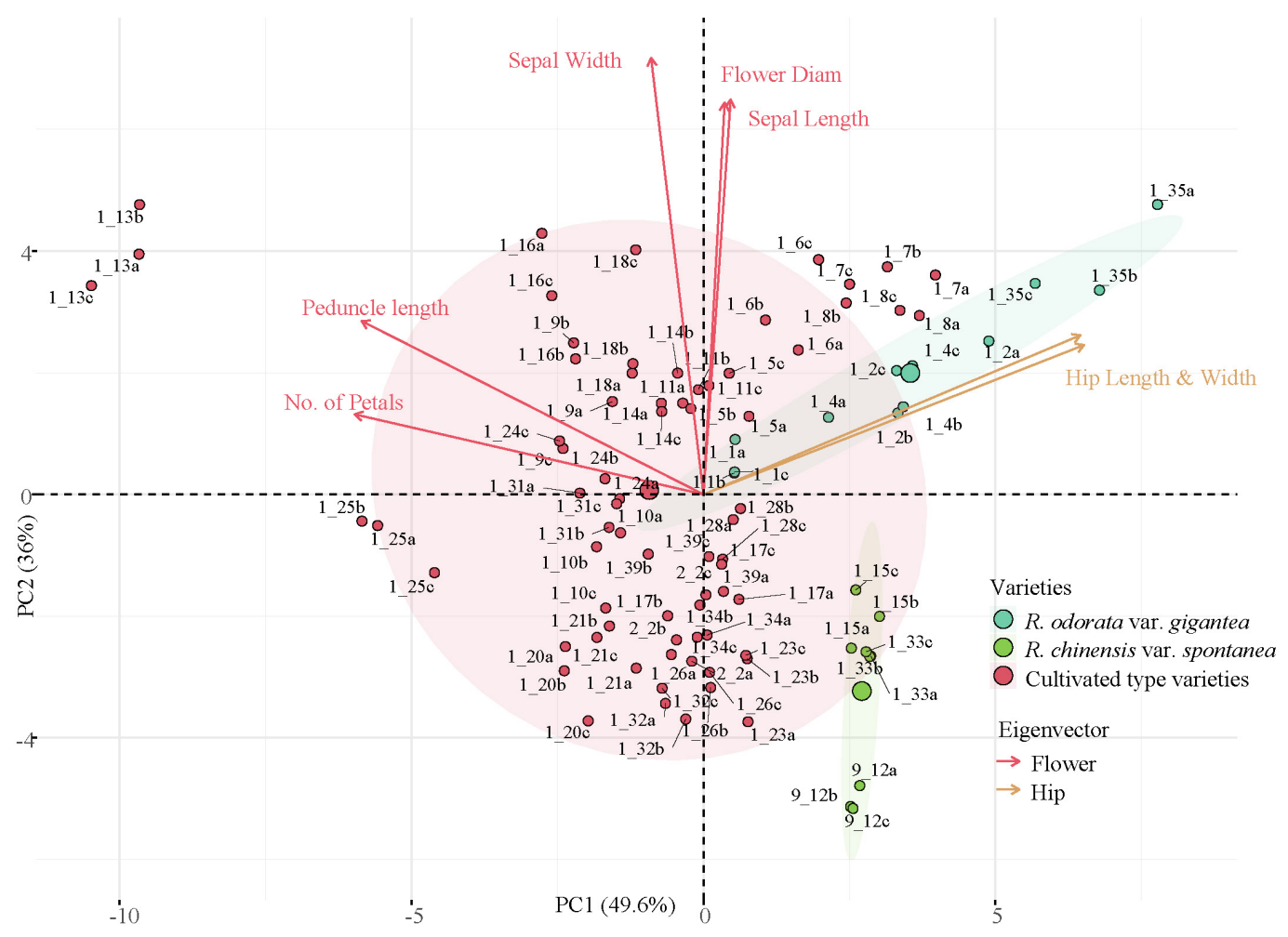

Figure 2. Principal component analysis of $R$. sect. Chinenses morphological characters. Letters behind the accessions numbers indicate the repeated experiments for each accessions. While the larger point indicate the center of the ellipse.

\subsection{Genetic Diversity of SSR Markers}

A total of 221 allelic variations were detected in 15 SSR loci in the materials tested, and each locus was polymorphic. The number of alleles ranged from seven to 26, with an average of 14.73 for each locus. The PIC ranged from 0.873 to 0.576 , with an average of 0.804 . They showed a high degree of genetic polymorphism in $R$. sect. Chinenses. These SSR loci could effectively distinguish different individuals.

The bottleneck effect was detected on three combinations of all accessions, the wild type accessions and the cultivated accessions (Table 4). The results showed that under the IAM evolutionary model, the combination of double petal accessions displayed an excess of heterozygosity at a significance level of 0.05 , indicating they had experienced a bottleneck effect. Under the TPM evolutionary model, this combination also displayed a bottleneck effect at a significance level of 0.1. Vegetative propagation in cultivation, multiple origins, and extensive hybridization could cause the bottleneck effect [6].

Table 4. Bottleneck effect of different combinations.

\begin{tabular}{clc}
\hline \multirow{2}{*}{ Test Combination } & \multicolumn{2}{c}{$p$ Value of Wilcoxon Sign-Rank Test } \\
\cline { 2 - 3 } & IAM & TPM \\
\hline All accessions & 0.06372 & 0.33026 \\
Cultivated type & 0.03534 & 0.08325 \\
Wild type & 0.84692 & 0.10700 \\
\hline IAM Infinite allele model, TPM Two-phase mutation model [34].
\end{tabular}

The genetic structure analysis (Figure 3) identified that the best $\mathrm{K}$ was four (Figure 4). The genetic structure was graphed according to the biological classification of the accessions. The results showed 
that when $\mathrm{K}=2$, R. chinensis and R. odorata were composed of different ancestral components, while the $R$. sect. Chinenses complex contained two components. When $\mathrm{K}=3$, R. odorata was composed of two different ancestral groups, while the $R$. sect. Chinenses complex contained three components. When $\mathrm{K}=4$, accessions with a higher degree of heterozygosity in the $R$. sect. Chinenses complex formed a new component. In addition, an accession of $R$. chinensis var. spontanea (labeled with * in the figure) with European provenance showed different components.
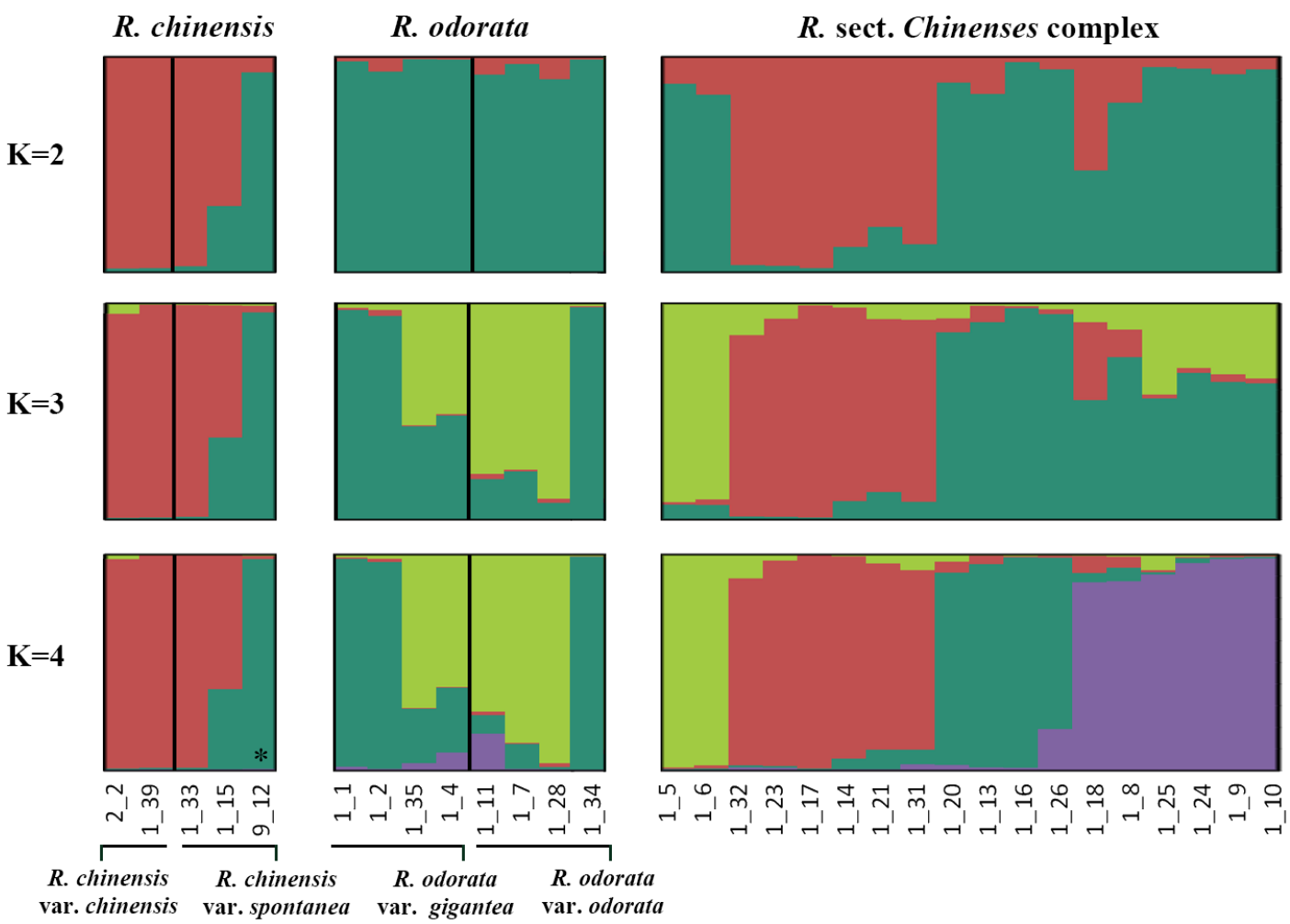

Figure 3. Genetic structure of $R$. sect. Chinenses.

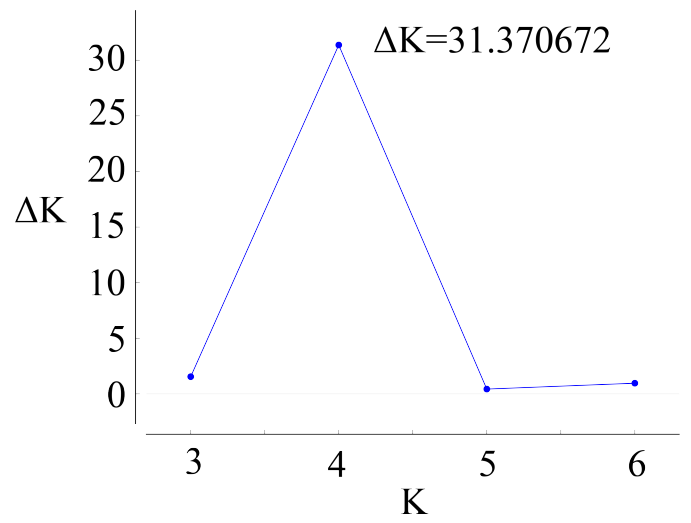

Figure 4. The value of delta K (averaged across 8 runs) obtained from STRUCTURE software [35].

\subsection{Screening of SCGs}

A total of 363 SCGs were screened from the 'Old Blush' genome (Figure 5), and two genes on each linkage group were selected for primer design and fragment amplification. Four SCG markers with high amplification efficiency and sequencing accuracy were used in the following study. 

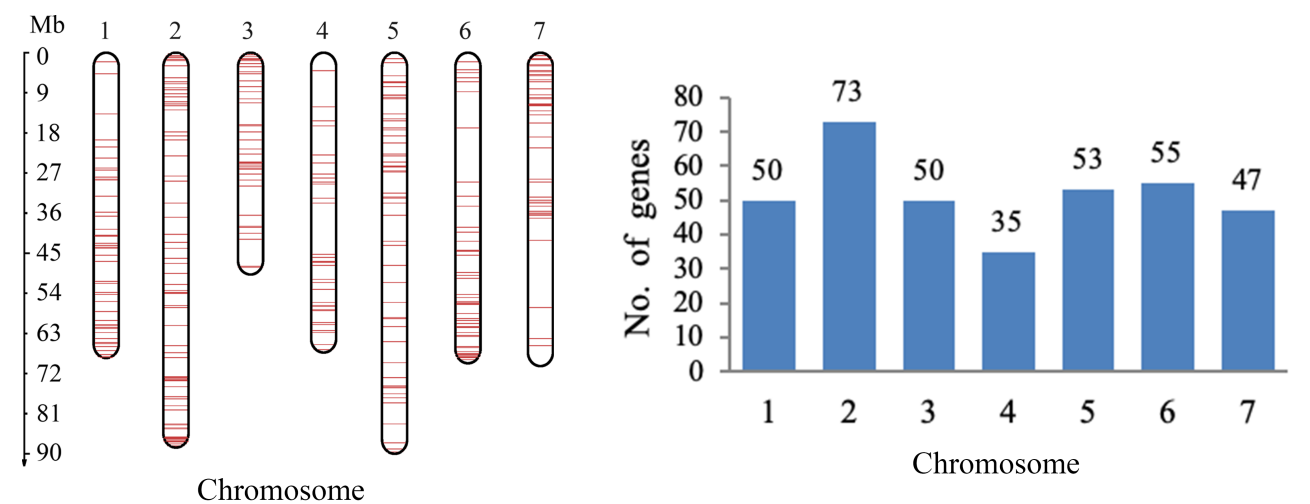

Figure 5. Distribution of the 363 studied single-copy nuclear genes (SCGs) in the 'Old Blush' genome.

\subsection{Phylogenetic Analysis}

The genetic diversity of each locus was calculated (Table 3). Due to different genetic patterns between chloroplast and nuclear genes, the two types of markers were separately assembled, aligned, and analyzed phylogenetically.

Based on the results of haplotype analysis on chloroplast genes, all accessions could be divided into 14 haplotypes (H1 to H14) (Figure 6), in which H1 to H9 were the haplotypes of sect. Chinenses, $\mathrm{H} 10$ to $\mathrm{H} 14$ were the outgroup haplotypes. No common ancestor was found for $\mathrm{H} 10$ from R. multiflora between other outgroups. $R$. odorata var. gigantea and $R$. chinensis var. spontanea accessions belong to $\mathrm{H} 1$ and $\mathrm{H} 5$ respectively. $\mathrm{H} 1$ and $\mathrm{H} 8$ were identified in the cultivated type of $\mathrm{R}$. odorata, and $\mathrm{H} 8$ and $\mathrm{H} 1$ were derived from the very close common missing haplotype. $\mathrm{H} 2, \mathrm{H} 3, \mathrm{H} 4, \mathrm{H} 6, \mathrm{H} 7$, and $\mathrm{H} 9$ of the remaining cultivated type were mutated from $\mathrm{H} 5$ ( $R$. chinensis var. spontanea).

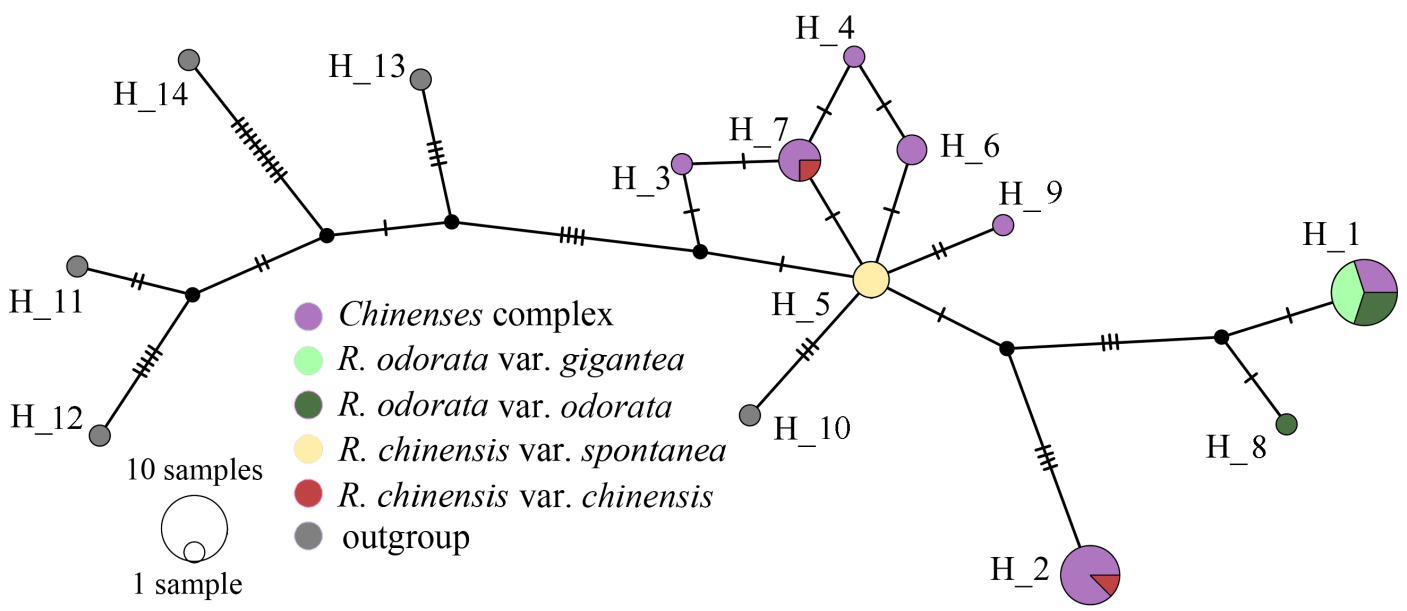

Figure 6. Haplotype network of $R$. sect. Chinenses based on chloroplast markers.

The phylogenetic analysis of chloroplast sequences revealed four main clades (Figure 7). Clade I contained all $R$. odorata accessions and reference sequences. Clades II and III were composed of the $R$. sect. Chinenses complex. R. chinensis var. spontanea formed several independent branches, indicating that these accessions were more ancestral. R. multiflora (section Synstylae) was not clustered in the outgroup clade but in different positions within the in-group.

The phylogenetic analysis based on SCGs resolved five main clades (Figure 8). Clade I contained the $R$. sect. Chinenses complex, two $R$. chinensis accessions, and two $R$. odorata accessions. Clade II contained two $R$. odorata accessions and some accessions from the $R$. sect. Chinenses complex. Clade III contained R. chinensis var. spontanea and R. lucieae. Another R. chinensis var. spontanea accession was located in clade IV together with two accessions from the $R$. sect. Chinenses complex. 


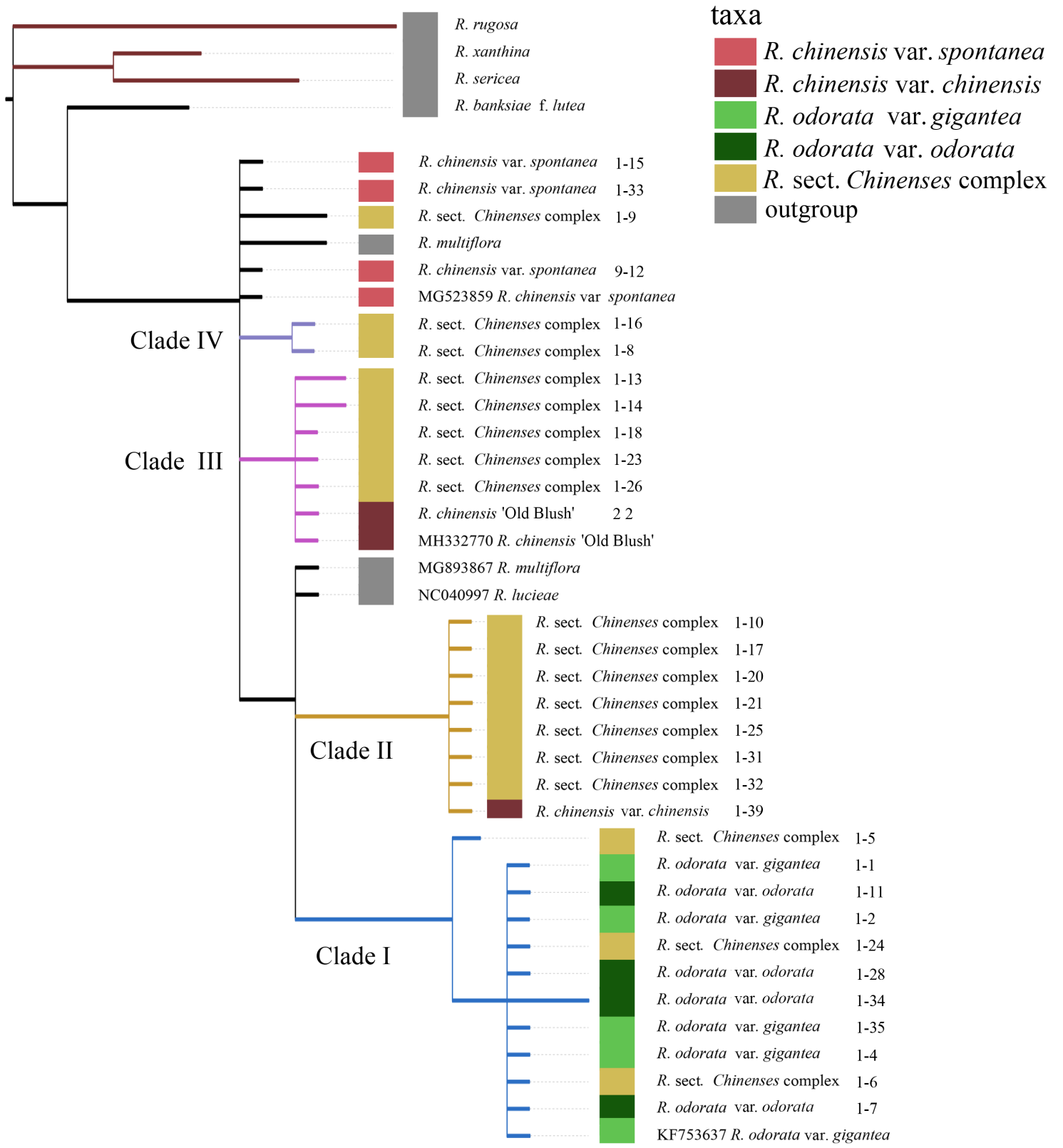

Figure 7. Phylogenetic analysis of $R$. sect. Chinenses based on chloroplast markers. 


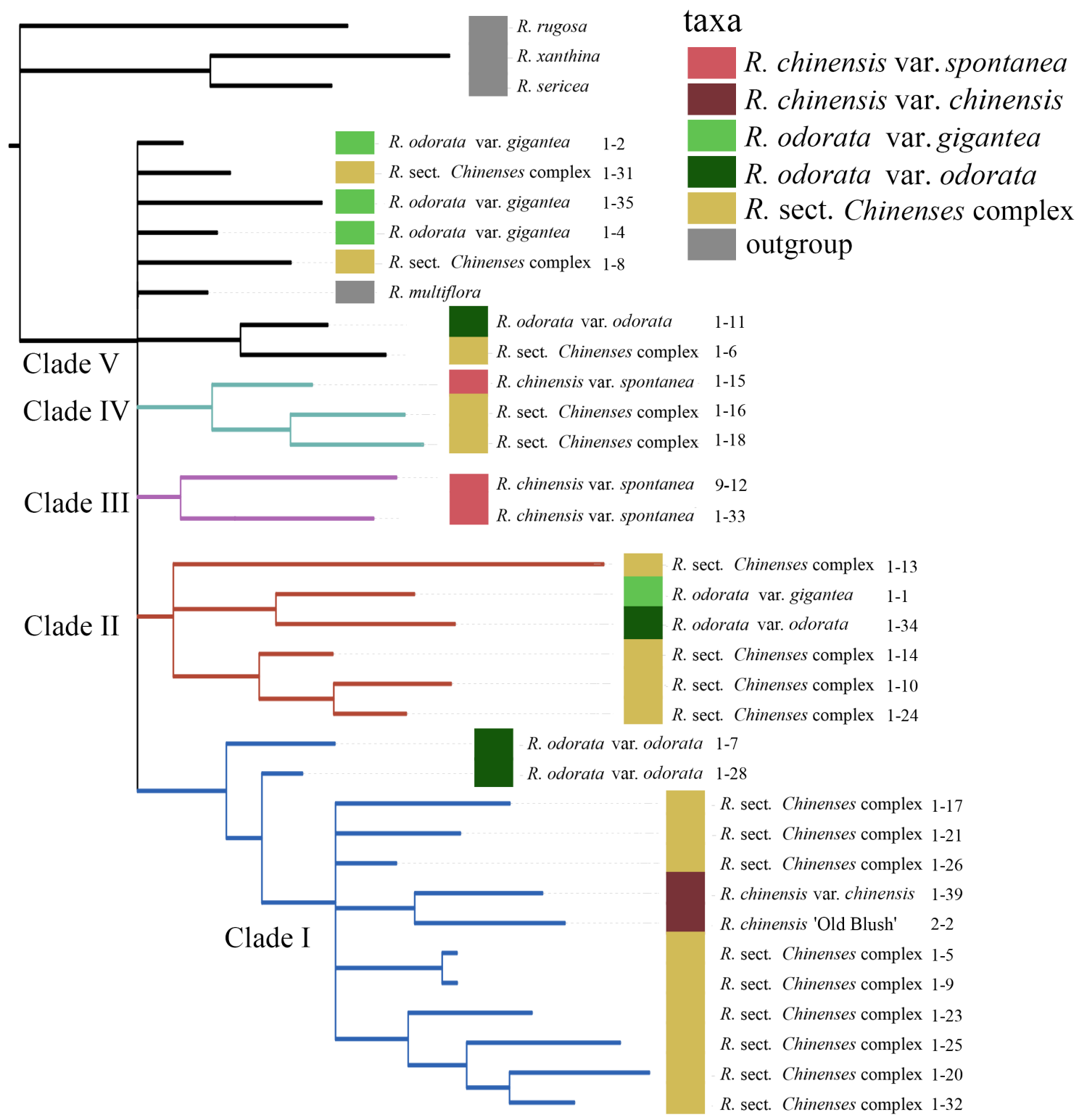

Figure 8. Phylogenetic analysis of $R$. sect. Chinenses based on single copy nuclear gene markers.

\section{Discussion}

\subsection{Origin of Cultivation of the China Rose}

The genetic diversity in rose encompasses two sources: wild species and cultivars [48]. R. odorata var. gigantea and $R$. chinensis var. spontanea are the wild types of $R$. sect. Chinenses. China roses have undergone thousands of years of cultivation. The flower type of China roses is simlar to that of cultivated type varieties. The cultivated types has been predicted to include the transition varieties produced in the breeding process. Alternatively, they could be the new varieties generated by hybridization between cultivated rose and wild species. Some cultivars have been identified as potential hybrid varieties [5]. The genetic structure analysis showed that $R$. chinensis and $R$. odorata possessed distinct genetic backgrounds, while the $R$. sect. Chinenses complex was heterozygous with two species, suggesting that these accessions may be hybrids of $R$. chinensis and R. odorata. Owing to the influence of geographical isolation of the Red River Fault Zone, two evolutionary significant units were identified in $R$. odorata var. gigantea [49]. In this study, the geographical distribution of $R$. odorata var. gigantea was consistent with the description above. No correlation between the genetic background and geographical location was found in cultivated type of $R$. odorata. 
Chloroplast markers are maternally inherited and are not affected by hybridization factors. The haplotype analysis suggested that six out of the seven haplotypes of cultivated type varieties were derived from $R$. chinensis var. spontanea, and only one haplotype was shared with $R$. odorata var. gigantea. These findings indicated that most of the accessions have maternal genetic background similar to $R$. chinensis var. spontanea. The haplotypes of cultivated type $R$. odorata were derived from $R$. odorata var. gigantea, but nuclear gene markers showed that the genetic background was inconsistent with that of $R$. odorata var. gigantea.

Previously published phylogenetic studies of Rosa showed that $R$. sects Synstylae and Chinenses were closely related. The two sections were often embedded together [15,50-52] or became sister clades [19], and $R$. sect. Synstylae may have participated in the formation of $R$. sect. Chinenses varieties [5,18]. In this study, R. multiflora from Synstylae did not form a clade with other outgroups but appeared in the sect. Chinenses clade. This indicated that $R$. multiflora may be involved in the hybridization of sect. Chinenses varieties. However, owing to the limitation of experimental materials, it was difficult to explain the relationship between $R$. multiflora and $R$. sect. Chinenses in more detail. Future studies should include more materials from $R$. sect. Synstylae to further clarify the phylogenetic relationships.

\subsection{Variation of Phenotypic Characters of Cultivated Type Varieties}

The analysis of phenotypic characters suggested significant differences in phenotypes between the wild type and cultivated types. A comparison of differences among species revealed that the flower diameter of $R$. odorata was significantly greater than that of $R$. chinensis. For the comparison of differences between wild type and cultivated types, the diameter of flower of cultivated types was found to be larger than that of its maternal parent, $R$. chinensis var. spontanea. A previous study showed that the inheritance of flower diameter was directly related to the number of petals and is affected by the additive effect of dominant genes [53]. The hip of the cultivated varieties was significantly smaller than that of the two wild type roses, indicating that the hip size of $R$. sect. Chinenses accessions decreased over the course of cultivation.

We found that no trait for fasciculate inflorescence existed in the wild type varieties, whereas a trait for fasciculate inflorescence existed in the cultivated type varieties. These results suggested that the phenotypes of fasciculate inflorescence appeared gradually with the continuous occurrence of artificial or natural hybridization. The pattern of genetic inheritance of rose inflorescences is currently unknown and two independent developmental pathways were related to it. Diverse variations in inflorescences have been observed in Rosa species, such as $R$. multiflora with panicles. While these wild roses might have participated in the hybridization of $R$. chinensis cultivars [5], this trait may be derived from other Rosa species.

\subsection{Role of Rose Germplasm Resources}

Germplasm resources are the basis for ornamental plant breeding. Although $R$. sect. Chinenses have contributed significantly to modern rose breeding throughout the world, a large amount of germplasm resources has not been fully explored and utilized. $R$. sect. Chinenses are being widely cultivated in many places across China. These germplasm resources are rich in ornamental traits and have substantial potential for molecular breeding research. However, owing to the complex genetic backgrounds and traits partially shared by different species, their taxonomic status is difficult to determine, and they were previously divided into different infraspecific levels [3,54]. The rose germplasm resources used in this study had the same characteristics. They were predicted to be transitional varieties produced during the breeding process or new varieties generated by further hybridization between cultivated and wild type accessions. These materials were of substantial significance to re-visit the breeding process of rose, the study of rose omics, the investigation of ornamental traits, the identification of functional genes, and hybrid breeding. 
Supplementary Materials: The following are available online at http:/ /www.mdpi.com/2073-4425/11/9/996/s1, Table S1: Primer information of molecular markers.

Author Contributions: Conceptualization, C.Y. (Chenyang Yang) and C.Y. (Chao Yu); Data curation, C.Y. (Chenyang Yang), Y.M. and B.C.; Formal analysis, C.Y. (Chenyang Yang) and Y.M.; Funding acquisition, C.Y. (Chao Yu) and Q.Z.; Investigation, C.Y. (Chenyang Yang), Y.M., B.C. and L.Z.; Project administration, C.Y. (Chao Yu) and Q.Z.; Resources, C.Y. (Chao Yu), L.L. and H.P.; Supervision, C.Y. (Chao Yu); Validation, Y.M.; Visualization, C.Y. (Chenyang Yang) and Y.M.; Writing-original draft, C.Y. (Chenyang Yang); Writing-review \& editing, C.Y. (Chenyang Yang), C.Y. (Chao Yu) and Q.Z. All authors have read and agreed to the published version of the manuscript.

Funding: This research was funded by National Key R\&D Program of China (2019YFD1000400).

Acknowledgments: We would like to thank Yang Yuyong (Kunming Yang Chinese Rose Gardening Co., Ltd.) for the help of collecting samples.

Conflicts of Interest: The authors declare no conflict of interest.

\section{References}

1. Wang, G.L. China's Ancient Rose; Science Press: Beijing, China, 2015.

2. Wissemann, V. Conventional taxonomy (wild roses). In Reference Module in Life Sciences; Reference Module in Life Sciences; Elsevier: Amsterdam, The Netherlands, 2017.

3. Ku, C.Z.; Robertson, K.R. Flora of China; Science Press: Beijing, China, 2003.

4. Roberts, A.V. Encyclopedia of Rose Science; Academic Press: San Diego, CA, USA, 2003.

5. Meng, J.; Fougere-Danezan, M.; Zhang, L.B.; Li, D.Z.; Yi, T.S. Untangling the hybrid origin of the Chinese tea roses: Evidence from DNA sequences of single-copy nuclear and chloroplast genes. Plant Syst. Evol. 2011, 297, 157-170. doi:10.1007/s00606-011-0504-5. [CrossRef]

6. Miller, A.J.; Gross, B.L. From forest to field: Perennial fruit crop domestication. Am. J. Bot. 2011, 98, 1389-1414. doi:10.3732/ajb.1000522. [CrossRef]

7. Wei, X.M.; Gao, X.F.; Zhang, L.B. A systematic study of Rosa sericea (Rosaceae) complex: Are R. omeiensis and R. sericea conspecific? J. Syst. Evol. 2008, 46, 919-928. doi:10.3724/SP.J.1002.2008.08046. [CrossRef]

8. Ahmadi, S.J.; Mortazaeinezhad, F.; Zeinali, H.; Askari-Khorasgani, O.; Pessarakli, M. Evaluation of various Rosa damascena mill. genotypes grown under rainfed semi-arid condition. Commun. Soil Sci. Plant Anal. 2019, 50, 2534-2543. doi:10.1080/00103624.2019.1667377. [CrossRef]

9. Vaezi, J.; Arjmandi, A.A.; Sharghi, H.R. Origin of Rosa x binaloudensis (Rosaceae), a new natural hybrid species from Iran. PhytoTaxa 2019, 411, 23-38. doi:10.11646/phytotaxa.411.1.2. [CrossRef]

10. Meng, J.; Li, D.; Yi, T.; Yang, J.; Zhao, X. Development and characterization of microsatellite loci for Rosa odorata var. gigantea Rehder \& E. H. Wilson (Rosaceae). Conserv. Genet. 2009, 10, 1973-1976. doi:10.1007/s10592-009-9871-7. [CrossRef]

11. Panwar, S.; Singh, K.P.; Namita.; Sonah, H.; Deshmukh, R.K.; Sharma, T.R. Identification and characterization of microsatellites in ESTs of Rosa species: Insight in development of SSR markers. Indian J. Agric. Sci. 2015, 85, 137-141.

12. Scariot, V.; Akkak, A.; Botta, R. Characterization and genetic relationships of wild species and old garden roses based on microsatellite analysis. J. Am. Soc. Hortic. Sci. 2006, 131, 66-73. doi:10.21273/JASHS.131.1.66. [CrossRef]

13. Liorzou, M.; Pernet, A.; Li, S.; Chastellier, A.; Thouroude, T.; Michel, G.; Malecot, V.; Gaillard, S.; Briee, C.; Foucher, F.; et al. Nineteenth century French rose (Rosa sp.) germplasm shows a shift over time from a European to an Asian genetic background. J. Exp. Bot. 2016, 67, 4711-4725. doi:10.1093/jxb/erw269. [CrossRef] [PubMed]

14. Joly, S.; Starr, J.R.; Lewis, W.H.; Bruneau, A. Polyploid and hybrid evolution in roses east of the Rocky Mountains. Am. J. Bot. 2006, 93, 412-425. doi:10.3732/ajb.93.3.412. [CrossRef] [PubMed]

15. Zhu, Z.M.; Gao, X.F.; Fougere-Danezan, M. Phylogeny of Rosa sections Chinenses and Synstylae (Rosaceae) based on chloroplast and nuclear markers. Mol. Phylogenetics Evol. 2015, 87, 50-64. doi:10.1016/j.ympev.2015.03.014. [CrossRef] [PubMed]

16. Martin, W.F.; Cerff, R. Physiology, phylogeny, early evolution, and GAPDH. Protoplasma 2017, 254, $1823-1834$. doi:10.1007/s00709-017-1095-y. [CrossRef] [PubMed] 
17. Hibrand Saint-Oyant, L.; Ruttink, T.; Hamama, L.; Kirov, I.; Lakhwani, D.; Zhou, N.N.; Bourke, P.M.; Daccord, N.; Leus, L.; Schulz, D.; et al. A high-quality genome sequence of Rosa chinensis to elucidate ornamental traits. Nat. Plants 2018, 4, 473-484. doi:10.1038/s41477-018-0166-1. [CrossRef] [PubMed]

18. Raymond, O.; Gouzy, J.; Just, J.; Badouin, H.; Verdenaud, M.; Lemainque, A.; Vergne, P.; Moja, S.; Choisne, N.; Pont, C.; et al. The Rosa genome provides new insights into the domestication of modern roses. Nat. Genet. 2018, 50, 772-777. doi:10.1038/s41588-018-0110-3. [CrossRef]

19. Debray, K.; Marie-Magdelaine, J.; Ruttink, T.; Clotault, J.; Foucher, F.; Malecot, V. Identification and assessment of variable single-copy orthologous (SCO) nuclear loci for low-level phylogenomics: A case study in the genus Rosa (Rosaceae). BMC Evol. Biol. 2019, 19. doi:10.1186/s12862-019-1479-z. [CrossRef] [PubMed]

20. Sang, T. Utility of low-copy nuclear gene sequences in plant phylogenetics. Crit. Rev. Biochem. Mol. Biol. 2002, 37, 121-147. doi:10.1080/10409230290771474. [CrossRef]

21. Reboud, X.; Zeyl, C. Organelle inheritance in plants. Heredity 1994, 72, 132-140. doi:10.1038/hdy.1994.19. [CrossRef]

22. Moe, R. Growth and flowering in roses. Acta Hortic. 1988, 218, 121-129. doi:10.17660/ActaHortic.1988.218.17. [CrossRef]

23. Nadeem, M.; Khan, M.A.; Riaz, A.; Ahmad, R. Evaluation of growth and flowering potential of Rosa Hybrida cultivars under faisalabad climatic conditions. Pak. J. Agric. Sci. 2011, 48, 283-288.

24. Liang, S.; Wu, X.; Byrne, D. Genetic analysis of flower size and production in diploid rose. J. Am. Soc. Hortic. Sci. 2017, 142, 306-313. doi:10.21273/JASHS04173-17. [CrossRef]

25. Lê, S.; Josse, J.; Husson, F. FactoMineR: A Package for Multivariate Analysis. J. Stat. Softw. 2008, 25, 1-18. doi:10.18637/jss.v025.i01. [CrossRef]

26. Yu, C. Construction of a Genetic Linkage Map and QTLs Analysis for Phenotypic Traits of Tetraploid Roses. PhD Thesis, Beijing Forestry University, Beijing, China, 2015.

27. Hibrand-Saint Oyant, L.; Crespel, L.; Rajapakse, S.; Zhang, L.; Foucher, F. Genetic linkage maps of rose constructed with new microsatellite markers and locating QTL controlling flowering traits. Tree Genet. Genomes 2008, 4, 11-23. doi:10.1007/s11295-007-0084-2. [CrossRef]

28. Taberlet, P.; Gielly, L.; Pautou, G.; Bouvet, J. Universal primers for amplification of three non-coding regions of chloroplast DNA. Plant Mol. Biol. 1991, 17, 1105-1109. doi:10.1007/BF00037152. [CrossRef]

29. Golenberg, E.M.; Clegg, M.T.; Durbin, M.L.; Doebley, J.; Ma, D.P. Evolution of a noncoding region of the chloroplast genome. Mol. Phylogenetics Evol. 1993, 2, 52-64. doi:10.1006/mpev.1993.1006. [CrossRef]

30. Duarte, J.M.; Wall, P.K.; Edger, P.P.; Landherr, L.L.; Ma, H.; Pires, J.C.; Leebens-Mack, J.; DePamphilis, C.W. Identification of shared single copy nuclear genes in Arabidopsis, Populus, Vitis and Oryza and their phylogenetic utility across various taxonomic levels. BMC Evol. Biol. 2010, 10. doi:10.1186/1471-2148-10-61. [CrossRef]

31. Camacho, C.; Coulouris, G.; Avagyan, V.; Ma, N.; Papadopoulos, J.; Bealer, K.; Madden, T.L. BLAST+: Architecture and applications. BMC Bioinform. 2009, 10, 421. doi:10.1186/1471-2105-10-421. [CrossRef]

32. AppliedBiosystems. GeneMapper Software 5, Client Installation. Available online: https://www. thermofisher.com / order / catalog/product/4366847?SID=srch-hj-4366847\#/ 4366847?SID=srch-hj-4366847 (accessed on 5 December 2019).

33. Peakall, R.; Smouse, P.E. GenAlEx 6.5: Genetic analysis in Excel. Population genetic software for teaching and research-an update. Bioinformatics 2012, 28, 2537-2539. doi:10.1093/bioinformatics/bts460. [CrossRef]

34. Piry, S.; Luikart, G.; Cornuet, J.M. Computer note. BOTTLENECK: A computer program for detecting recent reductions in the effective size using allele frequency data. J. Hered. 1999, 90, 502-503. doi:10.1093/jhered/90.4.502. [CrossRef]

35. Falush, D.; Stephens, M.; Pritchard, J.K. Inference of population structure using multilocus genotype data: dominant markers and null alleles. Mol. Ecol. Notes 2007, 7, 574-578. doi:10.1111/j.1471-8286.2007.01758.x. [CrossRef]

36. Earl, D.A.; VonHoldt, B.M. STRUCTURE HARVESTER: A website and program for visualizing STRUCTURE output and implementing the Evanno method. Conserv. Genet. Resour. 2012, 4, 359-361. doi:10.1007/s12686-011-9548-7. [CrossRef] 
37. Jakobsson, M.; Rosenberg, N.A. CLUMPP: A cluster matching and permutation program for dealing with label switching and multimodality in analysis of population structure. Bioinformatics 2007, 23, 1801-1806. doi:10.1093/bioinformatics/btm233. [CrossRef] [PubMed]

38. Katoh, K.; Standley, D.M. MAFFT multiple sequence alignment software version 7: Improvements in performance and usability. Mol. Biol. Evol. 2013, 30, 772-780. doi:10.1093/molbev/mst010. [CrossRef] [PubMed]

39. Rozas, J.; Ferrer-Mata, A.; Carlos Sanchez-DelBarrio, J.; Guirao-Rico, S.; Librado, P.; Ramos-Onsins, S.E.; Sanchez-Gracia, A. DnaSP 6: DNA sequence polymorphism analysis of large data sets. Mol. Biol. Evol. 2017, 34, 3299-3302. doi:10.1093/molbev/msx248. [CrossRef] [PubMed]

40. Zhang, D.; Gao, F.; Jakovlic, I.; Zou, H.; Zhang, J.; Li, W.X.; Wang, G.T. PhyloSuite: An integrated and scalable desktop platform for streamlined molecular sequence data management and evolutionary phylogenetics studies. Mol. Ecol. Resour. 2020, 20, 348-355. doi:10.1111/1755-0998.13096. [CrossRef] [PubMed]

41. Yang, J.B.; Li, D.Z.; Li, H.T. Highly effective sequencing whole chloroplast genomes of angiosperms by nine novel universal primer pairs. Mol. Ecol. Resour. 2014, 14, 1024-1031. [CrossRef]

42. Jian, H.Y.; Zhang, Y.H.; Yan, H.J.; Qiu, X.Q.; Wang, Q.G.; Li, S.B.; Zhang, S.D. The complete chloroplast genome of a key ancestor of Modern Roses, Rosa chinensis var. spontanea, and a comparison with congeneric species. Molecules 2018, 23, 389. doi:10.3390/molecules23020389. [CrossRef]

43. Jeon, J.H.; Kim, S.C. Comparative analysis of the complete chloroplast genome sequences of three closely related East-Asian wild roses (Rosa sect. Synstylae; Rosaceae). Genes 2019, 10, 23. doi:10.3390/genes10010023. [CrossRef]

44. Lanfear, R.; Frandsen, P.B.; Wright, A.M.; Senfeld, T.; Calcott, B. PartitionFinder 2: New methods for selecting partitioned models of evolution for molecular and morphological phylogenetic analyses. Mol. Biol. Evol. 2017, 34, 772-773. doi:10.1093/molbev/msw260. [CrossRef]

45. Ronquist, F.; Teslenko, M.; van der Mark, P.; Ayres, D.L.; Darling, A.; Hohna, S.; Larget, B.; Liu, L.; Suchard, M.A.; Huelsenbeck, J.P. MrBayes 3.2: Efficient bayesian phylogenetic inference and model choice across a large model space. Syst. Biol. 2012, 61, 539-542. doi:10.1093/sysbio/sys029. [CrossRef]

46. Leigh, J.W.; Bryant, D. POPART: Full-feature software for haplotype network construction. Methods Ecol. Evol. 2015, 6, 1110-1116. doi:10.1111/2041-210X.12410. [CrossRef]

47. Bandelt, H.J.; Forster, P.; Rohl, A. Median-joining networks for inferring intraspecific phylogenies. Mol. Biol. Evol. 1999, 16, 37-48. doi:10.1093/oxfordjournals.molbev.a026036. [CrossRef]

48. Smulders, M.J.M.; Arens, P.; Bourke, P.M.; Debener, T.; Linde, M.; De Riek, J.; Leus, L.; Ruttink, T.; Baudino, S.; Saint-Oyant, L.H.; et al. In the name of the rose: A roadmap for rose research in the genome era. Hortic. Res. 2019, 6. doi:10.1038/s41438-019-0156-0. [CrossRef] [PubMed]

49. Meng, J.; He, S.L.; Li, D.Z.; Yi, T.S. Nuclear genetic variation of Rosa odorata var. gigantea (Rosaceae): Population structure and conservation implications. Tree Genet. Genomes 2016, 12. doi:10.1007/s11295-016-1024-9. [CrossRef]

50. Wissemann, V.; Ritz, C.M. The genus Rosa (Rosoideae, Rosaceae) revisited: Molecular analysis of nrITS-1 and $a t p B-r b c L$ intergenic spacer (IGS) versus conventional taxonomy. Bot. J. Linn. Soc. 2005, 147, 275-290. doi:10.1111/j.1095-8339.2005.00368.x. [CrossRef]

51. Bruneau, A.; Starr, J.R.; Joly, S. Phylogenetic relationships in the genus Rosa: New evidence from chloroplast DNA sequences and an appraisal of current knowledge. Syst. Bot. 2007, 32, 366-378. doi:10.1600/036364407781179653. [CrossRef]

52. Fougere-Danezan, M.; Joly, S.; Bruneau, A.; Gao, X.F.; Zhang, L.B. Phylogeny and biogeography of wild roses with specific attention to polyploids. Ann. Bot. 2015, 115, 275-291. doi:10.1093/aob/mcu245. [CrossRef] 
53. Nadeem, M.; Younis, A.; Riaz, A.; Lim, K.B. Crossability among modern roses and heterosis of quantitative and qualitative traits in hybrids. Hortic. Environ. Biotechnol. 2015, 56, 487-497. doi:10.1007/s13580-015-0144-8. [CrossRef]

54. Rehder, A. Bibliography of Cultivated Trees and Shrubs Hardy in the Cooler Temperate Regions of the Northern Hemisphere; Arnold Arboretum of Harvard University: Boston, MA, USA, 1949. doi:10.5962/bhl.title.60035. [CrossRef]

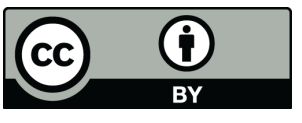

(C) 2020 by the authors. Licensee MDPI, Basel, Switzerland. This article is an open access article distributed under the terms and conditions of the Creative Commons Attribution (CC BY) license (http://creativecommons.org/licenses/by/4.0/). 